\title{
Emergence of dengue in Nepal
}

\author{
Birendra Prasad Gupta ${ }^{1,3} \cdot$ Mahesh Lamsal $^{1} \cdot$ Sudhikshya Chaulagain $^{1}$ • \\ Ramanuj Rauniyar $^{1} \cdot$ Rajani Malla $^{1} \cdot$ Smita Shrestha $^{1} \cdot$ Roshan Kurmi $^{2}$. \\ Krishna Das Manandhar ${ }^{1}$
}

Received: 15 May 2017/ Accepted: 7 February 2018/Published online: 17 February 2018

(C) Indian Virological Society 2018

\begin{abstract}
Dengue virus is a major health problem in Nepal. The endogenous dengue appeared in 2006 in the country with reported outbreaks in 2010, 2013 and 2016. Eleven years vertical data show there were sporadic cases in all the years and mostly adults between 25 and 40 years of age were infected with dengue virus. Compared with primary infections, secondary infections were observed in relatively larger numbers during the period of 2008-2016. Most of the cases had symptoms of dengue fever; while 7 and 19 cases demonstrated dengue hemorrhagic fever/dengue shock syndrome in 2010 and 2013 respectively. The proportion of dengue hemorrhagic fever amongst all cases of dengue fever was 2.5:4.7\% in 2010 and 2013. We found there is shift of serotype from dengue virus serotype1 (DENV-1) in 2010, DENV-2 in 2013 and DENV-1 in 2016. We feel there is urgent need for better community, hospital and laboratory based surveillance system capable of monitoring the circulating dengue virus (DENV) serotypes in different districts of Nepal. With improvement in surveillance system and efficient management of cases, the case fatality rate due to severe dengue can be reduced.
\end{abstract}

Keywords Dengue $\cdot$ Monsoon $\cdot$ Altitude $\cdot$ Climate change $\cdot$ Seroepidemiology

Krishna Das Manandhar

Krishna.manandhar@gmail.com

1 Virology Laboratory, Central Department of Biotechnology, Tribhuvan University, Kirtipur, Kathmandu, Nepal

2 Bhawani Hospital, Birgunj, Parsa, Nepal

3 Central Diagnostic Laboratory and Research Center Pvt. Ltd, Kathmandu, Nepal

\section{Introduction}

Dengue remains a major public health problem worldwide and the virus has been described as one of the most important arthropod-borne disease viruses [21]. The fever ailment, dengue fever (DF) is prevalent in sub-tropical and tropical countries with over 3.9 billion people being at risk of dengue virus infection worldwide [4]. WHO estimates that 50-100 million cases of DF and thousand cases of dengue hemorrhagic fever/dengue shock syndrome (DHF/ DSS) occur each year [1]. It has been particularly identified as a major problem of recent decades in the Asia Pacific and the Caribbean $[12,18]$. However in Africa, the specific epidemiology of dengue is not clear despite the vivid presence and distribution of its vector (Aedes spp.) which has been identified as the major risk factor associated with the prevalence of the viral infection in most part of the continent. The prevalence of dengue has been promoted by uncontrolled population growth, ineffective vector control, global warming as well as inadequate public health facilities [16]. Subsequently, this has led to a significant increase in the incidence of dengue worldwide [11]. At present, about 3.6 billion people are at risk of dengue, with up to 100 million cases annually [3]. Although most patients recover from dengue without complications, a high mortality rate of about 25,000 deaths per annum in children are associated with dengue [10, 22].

The cryptic stages of the dengue virus infection have potential to differentiate into DF as well life-threatening cases of DHF/DSS [2]. Amongst symptomatic patients, over $95 \%$ shows DF however only $6 \%$ of them progress to DHF which can lead to fatality among $1 \%$ of those symptomatic DHF cases $[17,19]$. DHF is one of the primary reasons for hospitalization and death among adults with secondary infection [28]. Dengue case of Nepal was 
first reported from a Japanese traveler after his return to his country in 2004 [27]. The first indigenous circulation of dengue virus infection which occurred during 2006 was from Banke district situated at the elevation of $362 \mathrm{~m}$ from sea level. Since then sporadic clinical cases of dengue are being reported every year with two major outbreaks in 2010, 2013 and 2016 [14, 24, 25]. The objective of this review paper is to summarize the sporadic and outbreak cases of Dengue in Nepal and emphasize that there should be need of active surveillance of Dengue in Nepal.

\section{Pattern of dengue in Nepal}

The first documentation of indigenous dengue in Nepal was in the year 2006 from Banke District, since then sporadic cases and/or outbreaks continued validating the DENV epidemics in the country. The dengue-wave spread from Chitwan and was yearly detected in the sub-tropical central western Terai region. Chitwan and Rupandehi District of central western region of Nepal were focal epidemics in 2010 outbreak. Until date the affected 29 districts are Arghakhanchi, Tanahu, Gorkha, Dhading, Kathmandu, Lalitpur, Makawanpur, Kaski, Palpa, Dadheldhura, Bhaktapur, Doti, Kanchanpur, Kailali, Bardiya, Banke, Dang, Kapilbastu, Ruphandehi, Nawalparasi, Chitwan, Parsa, Bara, Rautahat, Sarlahi, Mahottari, Saptari, Ilam and Jhapa [7].

The total numbers of confirmed cases and suspected patients are summarized in Fig. 1. Among them, all had DF, while 4, 8 and 12 cases respectively were of DHF/DSS in the outbreak-year 2010, 2013 and 2016. Mortality cases due to dengue have yet not been reported in Nepal since
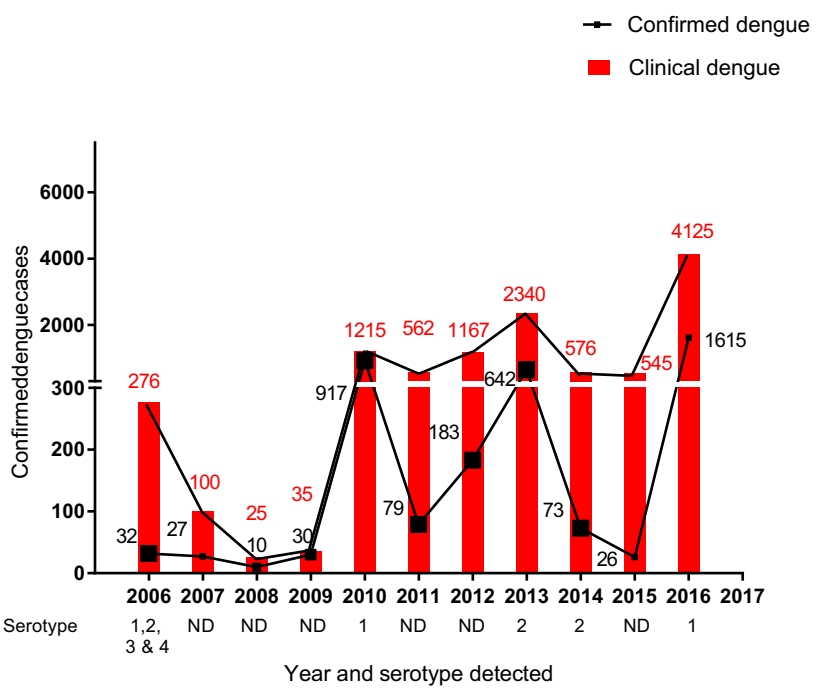

Fig. 1 Epidemiological curve showing the distribution of dengue suspected and confirmed cases from 2006 to 2016
2009; but Ministry of Health and family welfare, Government of Nepal reported 5 death in 2010, and 1 death in 2016 outbreaks which were contributed by predominant shift of serotypes from DENV-1 to DENV-2 and DENV-1 in 2010, 2013 and 2016 respectively [24, 25].

The number of primary dengue infection $(\mathrm{n}=25)$ was higher to the secondary $(n=7)$ in the year 2006 by 3.5 fold but had fourfold more secondary infection than primary in 2008 (Fig. 2). Then onwards from 2008, compared to primary infections, secondary were observed relatively in larger numbers till 2016 except for the year 2010 (513 vs 404), 2013 (478 vs 164), 2015 (12 vs 8) and 2016 (422 vs 245). The pattern observed was, frequency occurrence of primary infection $(\mathrm{n}=1598)$ was higher than secondary infection $(n=1082)$ irrespective to the virus serotype (Fig. 2). The maximum number of secondary dengue cases came from the Southern Terai districts, the open border with India's dengue endemic Northern states. Dengue hemorrhagic fever and dengue shock syndrome were found in the years of major outbreak in 2010, 2013 and 2016.

The general Nepalese population has very limited access to the health facilities because of political instability since many decades. The country lacks actual prevalence data of dengue because there are many unreported cases every year which might be due to insufficient manpower and limited availability of diagnostic kits at the health center/institutions. This may be driven by political instability and difficulties in the supply of the necessaries due to confines posed by the geographical regions of Nepal. Based on the literature, we found there is an increasing trend in the number of reported dengue cases, which have steadily increased from 32 laboratory confirmed case in 2006 to 4000 in 2016 according to the National Epidemiology and Disease control division, Ministry of Health, Government of Nepal. The 32 out of 75 districts of Nepal are now being considered endemic for dengue (Fig. 3) with repeated dengue outbreaks in every 3-4 years and sporadic cases every year.

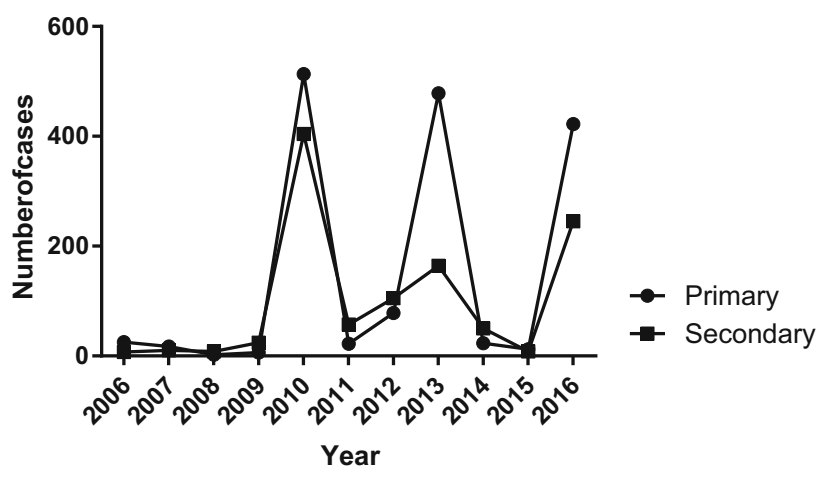

Fig. 2 Primary and secondary infection from 2006 to 2016 
Fig. 3 Dengue and Aedes aegypti confirmed districts from 2006 to 2016 in Nepal. *Hilly districts and red color shaded areas indicate dengue reported districts

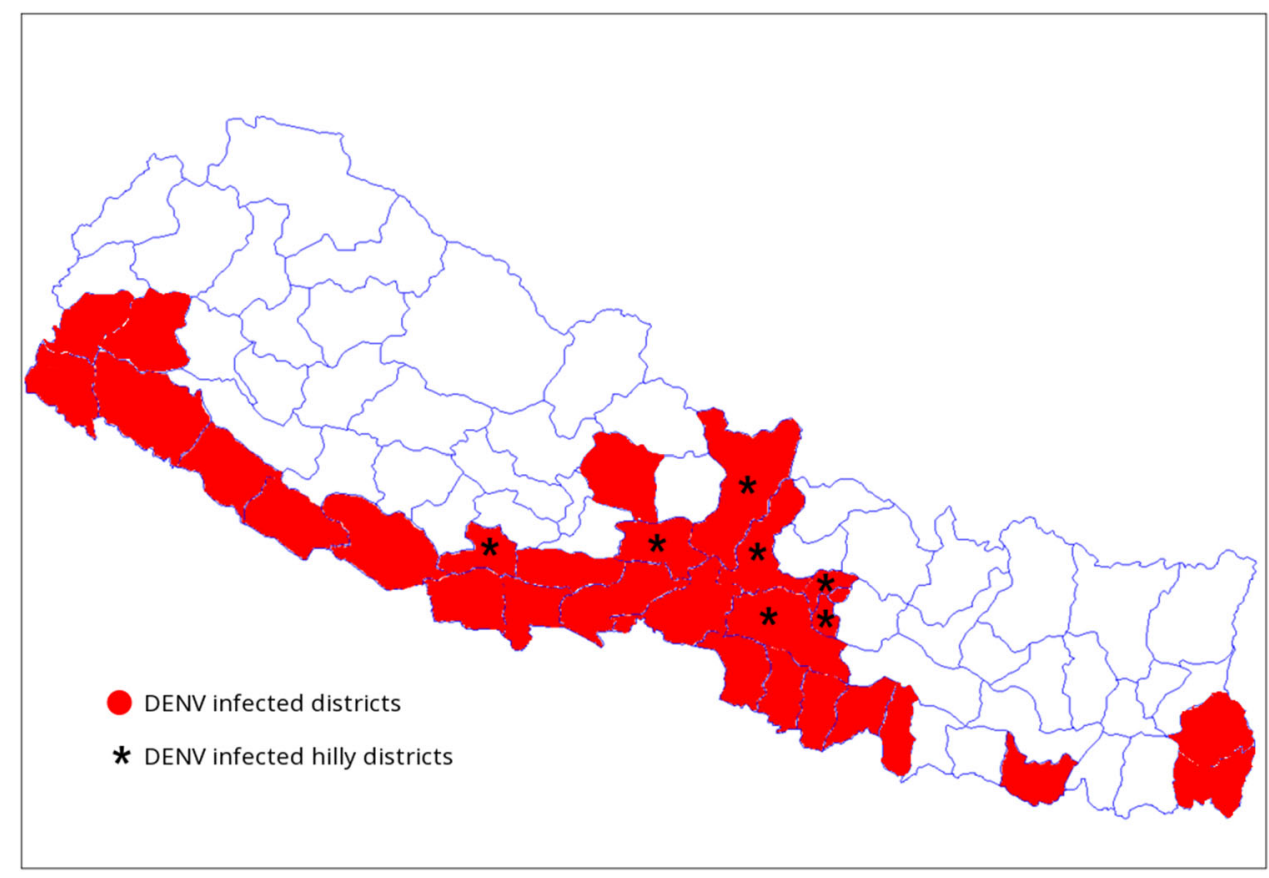

\section{Our perspective}

Dengue disease, an ancient vector born ailment has been increased by 30 -folds keeping $40 \%$ human population of the world at risk in more than 100 countries from the last five decades. Dengue virus could not be well understood since its isolation but continuing to spread to virgin areas becoming threat to mankind. It was fortunate that the disease could not instinct until twentieth century for Nepal. First dengue virus of Nepal was documented from Japan after 6 decades of its isolation from the country and interestingly, it was a coincidence that the ever first dengue virus infected individual was a Japanese traveler who visited Nepal in 2004. From 2006, every year Nepal is affected by the dengue disease with two major outbreaks in 2010, 2013 and 2016 AD. Trend of dengue epidemiology in Nepal showed that the dengue virus made a good jump in short span of time. The number of suspected dengue patients visited to hospitals reached to 9206 and 4026 $(43.73 \%)$ were found case positive in its 11 year history which is alarming for the peoples' health. The disease ventured to the country in 2006 in the indigenous people with a remarkable 32 confirmed cases. The virus then remained almost latent in the three consecutive years from 2007 to 2009 before a shock giving outbreak with 359 confirmed cases in 2010. Following the trend of dormancy after the outbreak, it exhibited its presence in the year 2011 $(\mathrm{n}=79)$ and $2012(\mathrm{n}=183)$ which led to burst as a huge outbreak in $2013(\mathrm{n}=315)$ and $2016(\mathrm{n}=4225)$. Hence, after Dengue's first impetus in 2006 and two major peaks in 2010, 2013 and 2016, it has shown clear cyclic amplitude in every 3 year. Fitting to the trend, the low incidences in the last 2014 and 2015 (unpublished data) could be taken as incubation period indicating a possible major severe burst in the coming next one and 2 years to complete a third cyclic outbreak. Such epidemiological cyclic outbreak-trend after every 3 year had been experienced by Brazil and Cuba in 1981 and 1986 respectively $[15,26]$.

The ever first record of Dengue was from Chitwan District, which covers different landscape from below $300 \mathrm{~m}$ to above $2000 \mathrm{~m}$ of the sea level and the place is also a popular touristic spot of Nepal. Chitwan and Rupandehi Districts of Central Western Region of Nepal were focal epidemics in 2010 outbreak. The disease then seen to other low land terai belt of the country including the most dengue affected Birganj (Parsa District, $80 \mathrm{~m}$ above sea level) of Nepal. The sub-metropolitan city is densely populated open transit route to North India facilitating easy transmission and imported cases. Besides, the subtropical climate favors the mosquitoes including Aedes spp. DENV vectors and DF cases have been recorded even from the middle mountain region $(1310 \mathrm{~m})$ of 8 districts, including Kathmandu out of 22 affected districts by 2014 and 32 districts in 2016. Kathmandu, the capital and heritage city of world in habituated by more than one million population belonging to the warm temperate zone had first report of local indigenous DF case in 2010 followed by a case of Bhimdhunga, Kathmandu (1450 m) in 2014 from the patient who had no travel history to known DF affected areas [7]. The reason behind for spreading the disease to temperate zone might be due to general climate. The reason 
behind for spreading the disease to temperate zone might be due to general global warming trend observed in Nepal as on a study data of the 36 years between 1971 and 2006 favoring the vector niche [8]. In addition, there is need of in-depth research of any genetic variation occurred in the viral adaptability.

Different geographical states have apparently different dengue vulnerable age group population. The Cebu province of Philippines had $81.7 \%$ dengue infection to the children below 15 year age group in their study from 1997 to 2008 [9] contrary to previous report in the province [5]. This 9 years vertical study of the dengue infection to the adults versus children in Nepalese context showed the adults of productive age group 27-35 were found more vulnerable which is increasing the DALYS of the country crippling its economy. However, this study of Nepal showed the population of 15-40 years was found as the most (81.4\%) infected one. Similar result of the age group 21-30 year was found most affected in a case study conducted in Delhi, India [6,13]. In the case of below 15 years in the last 2 year (2013 and 2014) dengue confirmed patients were 18 and $15.1 \%$ respectively which are at the higher range compared to the previous cases and is alarming signal to Nepalese health sector. Year wise study in regards to the sex based analysis clearly showed that the males were more exposed to the infection than female at mean ratio of $2: 1$ in this 9 year data in agreement to the past study by Gupta et al. [13]. The reason behind could be routine field works of male gender for livelihood of family bound to be exposed to Aedes spp. bite.

Seasonal variation trend of dengue epidemiology every year shows that it starts abruptly in the month of July just after the raining season and peaked in August and September which are the best favorable climate for mosquitoes. Cases start to decline from the month of October and no cases were seen by January (Fig. 1). Hence, the total infection period in Nepal is from the month July to December. Similar seasonal response was found in the study conducted in China from 2005 to 2014 and Cebu Province, Philippines having major infections between July to November [9]. Peak transmission in post monsoon season (Fig. 1) showed agreement to the study conducted in Nepal and Delhi, India [13, 23]. The distinct seasonal dengue trend of Nepal needs to be considered applying focused precautions and public awareness during the specific months in order to control possible future outbreaks.

Nepal has heterogeneity of multiple dengue serotypes as all four serotypes circulation were found in 2006. Since then, only a single serotype was found as predominant as in the year 2010 and 2016, it was DENV-1 while in 2004, 2013 and 2014, it was DENV-2. Similar type of serotype prevalence was seen in Delhi, India showing all four serotypes in 2003 followed by predominant serotype 3 in 2004 and 2005 [13]. Pakistan also had multiple serotypes in 2008 following predominant of single serotype of DENV3 in 2006-2007 [20]. In Nepal, all the study years had higher percentage of secondary infections except the dengue introduction year. Among the outbreaks, the year $2010 \mathrm{had}$ DENV-1 with $60 \%$ secondary infection and $6.7 \%$ (7 cases) of DHF while it was $66.6 \%, 3 \%$ (19 DHF cases) in 2013 of DENV-2 and 3\% (19 DHF cases) in 2016 of DENV-1. Almost all patients who visited Government hospital in the capital city of Nepal manifested the features of classical DF such as fever, headache and myalgia in the year 2010, 2013 and 2016. Hemorrhagic manifestations, the characteristic ailment of DHF were also noted in the form of ecchymosis, epistaxis, gum bleeding and gastrointestinal (GI) bleeding. In previous study it was noted that $20 \%$ of the patients experienced GI bleeding, abdominal pain, vomiting and difficulty in movement leading to hospitalization [24]. However, serious complications were minimal in 2013 outbreak that we had observed with only 15 patients out of the 198 cases $(7.5 \%)$ showed mucosal bleeding without mortality [14].

\section{Concluding remarks}

We emphasize, the Government of Nepal with support in collaboration with international organizations like World Heath Organizations (WHO), United Nation Development Program (UNDP) should initiate the active surveillance which may give the actual figure of circulating dengue cases in Nepal. Furthermore, a strong surveillance system needs to be in place before any vaccine trial takes place in endemic regions of Nepal and in addition to DENV serotype-based epidemiological data, adequate facts regarding the circulating serotype.

Acknowledgements The authors are grateful Virology Laboratory, Central Department of Biotechnology. We would like to thank Dr. Roshan Kurmi for clinical evaluation of dengue suspected patient from 2013 Dengue outbreak and EDCD for providing data.

\section{References}

1. Adesina OA, Adeniji JA. Incidence of dengue virus infections in febrile episodes in Ile-Ife, Nigeria. Afr $\mathrm{J}$ Infect Dis. 2016;10(1):21-4.

2. Back AT, Lundkvist A. Dengue viruses-an overview. Infect Ecol Epidemiol. 2013;3:19839.

3. Beauté J, Vong S. Cost and disease burden of dengue in Cambodia. BMC Public Health. 2010;10(1):521.

4. Brady OJ, Gething PW, Bhatt S, Messina JP, Brownstein JS, Hoen AG, Moyes CL, Farlow AW, Scott TW, Hay SI. Refining the global spatial limits of dengue virus transmission by evidence-based consensus. PLoS Negl Trop Dis. 2012;6(8):e1760. 
5. Bravo L, Roque VG, Brett J, Dizon R, L'Azou M. Epidemiology of dengue disease in the Philippines (2000-2011): a systematic literature review. PLoS Negl Trop Dis. 2014;8(11):e3027.

6. Chakravarti A, Kumaria R. Eco-epidemiological analysis of dengue infection during an outbreak of dengue fever, India. Virol J. 2005;2:32.

7. Gupta BP, Adhikari A, Rauniyar R, Kurmi R, Upadhya BP, Jha BK, Pandey B, Das Manandhar K. Dengue virus infection in a French traveller to the hilly region of Nepal in 2015: a case report. J Med Case Rep 2016;10:65. https://doi.org/10.1186/ s13256-016-0847-1.

8. Dhimal M, Gautam I, Kress A, Muller R, Kuch U. Spatio-temporal distribution of dengue and lymphatic filariasis vectors along an altitudinal transect in Central Nepal. PLoS Negl Trop Dis. 2014;8(7):e3035.

9. Edillo FE, Halasa YA, Largo FM, Erasmo JN, Amoin NB, Alera MT, Yoon IK, Alcantara AC, Shepard DS. Economic cost and burden of dengue in the Philippines. Am J Trop Med Hyg. 2015;92(2):360-6.

10. Gibbons RV, Vaughn DW. Dengue: an escalating problem. BMJ Br Med J. 2002;324(7353):1563.

11. Gubler DJ. Resurgent vector-borne diseases as a global health problem. Emerg Infect Dis. 1998;4(3):442.

12. Gubler DJ. The changing epidemiology of yellow fever and dengue, 1900 to 2003: full circle? Comp Immunol Microbiol Infect Dis. 2004;27(5):319-30.

13. Gupta E, Dar L, Kapoor G, Broor S. The changing epidemiology of dengue in Delhi, India. Virol J. 2006;3:92.

14. Gupta BP, Singh S, Kurmi R, Malla R, Sreekumar E, Manandhar KD. Re-emergence of dengue virus serotype 2 strains in the 2013 outbreak in Nepal. Indian J Med Res. 2015;142(Suppl):S1-6.

15. Guzman MG, Kouri G, Valdes L, Bravo J, Vazquez S, Halstead SB. Enhanced severity of secondary dengue-2 infections: death rates in 1981 and 1997 Cuban outbreaks. Rev Panam Salud Pública. 2002;11(4):223-7.

16. Guzman MG, Halstead SB, Artsob H, Buchy P, Farrar J, Gubler DJ, Hunsperger E, Kroeger A, Margolis HS, Martínez E. Dengue: a continuing global threat. Nat Rev Microbiol. 2010;8:S7-16.
17. Hadinegoro SR. The revised WHO dengue case classification: does the system need to be modified? Paediatr Int Child Health. 2012;32(Suppl 1):33-8.

18. Valdés I, Marcos E, Suzarte E, Pérez Y, Brown E, Lazo L, Cobas K, Yaugel M, Rodríguez Y, Gil L, Guillén G, Hermida L. A doseresponse study in mice of a tetravalent vaccine candidate composed of domain III-capsid proteins from dengue viruses. Arch Virol 2017;162(8):2247-56.

19. Kalayanarooj S. Clinical manifestations and management of dengue/DHF/DSS. Trop Med Health. 2011;39(4 Suppl):83-7.

20. Koo C, Nasir A, Hapuarachchi HC, Lee KS, Hasan Z, Ng LC, Khan E. Evolution and heterogeneity of multiple serotypes of dengue virus in Pakistan, 2006-2011. Virol J. 2013;10:275.

21. Malavige GN, Fernando S, Fernando DJ, Seneviratne SL. Dengue viral infections. Postgrad Med J. 2004;80(948):588-601.

22. Murray NEA, Quam MB, Wilder-Smith A. Epidemiology of dengue: past, present and future prospects. Clin Epidemiol. 2013;5:299.

23. Pandey BD, Morita K, Khanal SR, Takasaki T, Miyazaki I, Ogawa T, Inoue S, Kurane I. Dengue virus, Nepal. Emerg Infect Dis. 2008;14(3):514-5.

24. Pandey BD, Nabeshima T, Pandey K, Rajendra SP, Shah Y, Adhikari BR, Gupta G, Gautam I, Tun MM, Uchida R, et al. First isolation of dengue virus from the 2010 epidemic in Nepal. Trop Med Health. 2013;41(3):103-11.

25. Singh S, Gupta BP, Manakkadan A, Das Manandhar K, Sreekumar E. Phylogenetic study reveals co-circulation of Asian II and Cosmopolitan genotypes of dengue virus serotype 2 in Nepal during 2013. Infect Genet Evol. 2015;34:402-9.

26. Siqueira JB Jr., Martelli CM, Coelho GE, Simplicio AC, Hatch DL. Dengue and dengue hemorrhagic fever, Brazil, 1981-2002. Emerg Infect Dis. 2005;11(1):48-53.

27. Takasaki T, Kotaki A, Nishimura K, Sato Y, Tokuda A, Lim CK, Ito M, Tajima S, Nerome R, Kurane I. Dengue virus type 2 isolated from an imported dengue patient in Japan: first isolation of dengue virus from Nepal. J Travel Med. 2008;15(1):46-9.

28. Tantawichien T. Dengue fever and dengue haemorrhagic fever in adolescents and adults. Paediatr Int Child Health. 2012;32(Suppl 1):22-7. 